\title{
The Latina Project: Adolescent and Parent Perceptions of Successful Teen Pregnancy Prevention Programs
}

\author{
M. S. Madlem ${ }^{1}$, Cathy Bambrick ${ }^{2}$, Erin Fishburn ${ }^{3}$, Samantha Ball-Garza ${ }^{3}$, \\ Jani Iverson ${ }^{3}$, Mary Pellicer \\ ${ }^{1}$ Central Washington University \\ ${ }^{2}$ Clarity Consulting \\ ${ }^{3}$ Planned Parenthood of Central Washington
}

\begin{abstract}
The Hispanic population is rapidly growing in the U.S. The health issues that challenge this population are often unique. Pregnancy rates among Hispanic teens have remained steady or risen in some areas. Yakima County, Washington has the highest teen pregnancy rate for women aged 18-19 of any county in the state (182.72 per 1000 women compared with 104.32 per 1000 women in Washington). Over half of the births in this age range are to Hispanic teens. For these reasons, Planned Parenthood of Central Washington, with funding from the Centers for Disease Control and Prevention, collaborated with Central Washington University to conduct formative research on Hispanic teen pregnancy prevention. This qualitative focus group study revealed perceptions of adolescents and parents of communication patterns, desired content of sexuality education programs, and the provision of sexuality education programming. Understanding these perceptions may be the first step in developing educational programs that have a positive impact on Latina teens.
\end{abstract}

(C) 2003 Californian Journal of Health Promotion. All rights reserved.

Keywords: Hispanic teen health, teen health, sexuality education, pregnancy prevention

Teen pregnancy rates are at record low levels in the United States. Boonstra (2002) reported that in 1990 , the rate of teen pregnancy was 117 pregnancies per 1,000 women aged 15-19. The rate declined 19\% in 1997 (93 pregnancies per 1000 women). In 2000 the rate of teen childbearing declined to an all time low of 49 per 1000 women. The U.S. teen abortion rate in 1997 was also 33\% lower than the rate a decade earlier. Yet the United States continues to have the highest teen pregnancy rate of developed countries.

Although teen pregnancy rates have steadily declined across the population in the United States, pregnancy rates among Hispanic teens have remained steady or risen in some geographic areas. Close to half of U.S. Latino high school students report they are sexually active (CDC, 2000). Yakima County,
Washington has one of the largest Hispanic populations in the state and the highest teen pregnancy rate for women aged 18-19 (182.72 per 1000 women compared with 104.32 per 1000 women in Washington). Over half of the births in this age range are to Hispanic teens.

Understanding the perceptions of the Hispanic teen population is an important first step in developing teen pregnancy prevention programs for this population. Indeed it was the purpose of this study; to gain information on the perceptions of Hispanic adolescents of teen pregnancy prevention programs. Of particular interest were perceptions of who Hispanic teens felt safe and comfortable talking with about their problems and who provided them sexuality education. A final interest area was exploring what information Hispanic teens thought important in pregnancy prevention programs 
designed for their parent. This study was unique in that it asked open-ended questions of both adolescents and the parent/guardian of adolescents.

Researchers chose a focus group design for this formative study. Specific objectives of groups were to: a) gain an understanding of who adolescents felt safe or comfortable talking about their problems, b) understand adolescent's perceptions of critical components of teen pregnancy prevention, c) establish parents' understanding of who teenagers felt safe or comfortable talking with about their problems, d) ascertain parents' attitude toward components of sexuality education, e) identify who adolescents report provided them sexuality education, and f) identify who parents report provides sexuality education to their child.

\section{Method}

\section{Participants}

There were 29 adolescents aged 11-14 and 44 parents of this age group and 45 adolescents age 15-19 and 11 parents of this age group that participated in the focus groups.

\section{Recruitment}

Participants were recruited via Hispanic Radio stations and flyers posted in community centers around neighborhoods with high Latino populations. Volunteers were asked to call a toll free number for more information. A Spanishspeaking researcher staffed the phone, answered questions, and randomly assigned participants to a focus group meeting place and time. All participants were required to sign informed consent forms in accordance with procedures outlined by the Human Subjects Committee.

\section{Focus Groups}

Participants were divided into focus groups by gender and by roles (parent-adolescent). Researchers felt that the discussion of sensitive issues in mixed gender settings might compromise the reliability of the data (Schust, 1997). Focus group questions were generated from a review of the literature available on Latino adolescent teen pregnancy (Goodyear, Newcomb, \& Allison, 2000; O'Donnell et al., 1999; Santelli, Lowry, Brener, \& Robin, 2000). (see Table 1) A bilingual moderator facilitated questions and discussion. A second bilingual moderator took notes, ran audio taping equipment, and attended to logistical issues that arose. The majority of adolescent groups were conducted in English. The majority of the parent groups were conducted in Spanish.

\section{Analysis}

Audiotapes of focus group discussions and notes from the second moderator of the groups were transcribed. Groups conducted in Spanish were translated into English by professional Spanish transcriptionists familiar with the local dialect. A systematic review of the transcripts took place, with coding following general content analysis procedures. Categories of persons that adolescents feel safe or comfortable talking to about their problems were compared with parents' beliefs of whom their child talked with. Content of sexuality education programs that adolescents thought necessary were compared with parental perceptions of necessary content. Sources of sexuality information were juxtaposed comparing older adolescents with parents of older adolescents.

\section{Results}

Adolescents aged 11-14 reports of who they felt safe or comfortable talking with about their problems.

All groups (males and females) reported feeling safe or comfortable talking with their mothers. This was especially evident when asked specifically whom they feel safe talking to about their health problems. One teen revealed, "She is somebody you can depend on. She is right there whenever you need her. Because she is like stuck to you." Another stated, "My parents understand me. Like when I want to say something, like I'm sad, or I have something happen at our school that I don't want to really say, I go to my parents and they understand me." Family members such as fathers, sisters, brothers, aunts, uncles, cousins, and godmothers were also mentioned, as were other adults such as teachers, guidance counselors, and pastors. One teen, when asked directly if they were more comfortable with a parent or the school stated, "My parents." 
"Friends were also mentioned as trusted confidants. One teen revealed, "I call my friends about everything." Another stated, "I usually tell all my problems to my friends." Another confirmed this by stating, "With all my friends, I just talk to them."

Table 1

Focus Group Questions For Each Group Sampled

\begin{tabular}{|c|c|}
\hline Group & Question \\
\hline \multirow[t]{2}{*}{ Teens ages $11-14$} & 1. Who do you feel safe or comfortable talking to about your problems? \\
\hline & $\begin{array}{l}\text { 2. What do you think should be included in a sexuality education program for } \\
\text { your parents? }\end{array}$ \\
\hline \multirow[t]{3}{*}{ Teens ages $15-19$} & $\begin{array}{l}\text { 1. When you were } 11-14 \text { years old, who did you feel safe or comfortable talking } \\
\text { to about your problems? }\end{array}$ \\
\hline & $\begin{array}{l}\text { 2. What do you think should be included in a sexuality education program for } \\
\text { your parents? }\end{array}$ \\
\hline & 3. Who provided sexuality education to you? \\
\hline \multirow[t]{2}{*}{$\begin{array}{l}\text { Parents of children } \\
\text { ages } 11-14\end{array}$} & $\begin{array}{l}\text { 1. Who does your child feel safe or comfortable talking to about his/her } \\
\text { problems? }\end{array}$ \\
\hline & $\begin{array}{l}\text { 2. What do you think makes a successful teen pregnancy program for our } \\
\text { Hispanic youth? }\end{array}$ \\
\hline \multirow[t]{3}{*}{$\begin{array}{l}\text { Parents of children } \\
\text { ages } 15-19\end{array}$} & $\begin{array}{l}\text { 1. When your child was age } 11-14 \text {, who did he/she feel safe or comfortable } \\
\text { talking to about his/her problems? }\end{array}$ \\
\hline & $\begin{array}{l}\text { 2. What do you think makes a successful teen pregnancy program for our } \\
\text { Hispanic youth? }\end{array}$ \\
\hline & $\begin{array}{l}\text { 3. When your child was 11-14 years old, did anyone provide sexuality education } \\
\text { for him/her? }\end{array}$ \\
\hline
\end{tabular}

Parents' perceptions of who their children aged 11-14 felt safe or comfortable talking with about their problems.

Most parents felt that their child came to them with his/her problems. One parent stated, "I always tell her, I am her mother and friend, and she needs to trust me. I will not reprimand her. You need to trust and talk to me." Another parent followed, "The father is the best base, they should trust dad." Parents also named other family members as trusted confidants of their children, i.e., brothers, uncles, sisters, grandmothers, and godmothers.

Friends were also mentioned by parents. One parent expressed, "In my case I think we need a person outside the home, outside the problem." Another followed with, "Because my daughter may have things that she is not capable to tell me, I ask for help to my godmother."
Adolescents aged 15-19 reports of who they felt safe or comfortable talking with about their problems.

Respondents reported that they felt comfortable talking with their parent(s). One teen stated, "I feel comfortable just with my parents. I still do. Whatever I do, I tell them. I don't like lying to them. I feel guilty." Another followed, "I can talk with my mom about everything." Still another stated, "The family is always there." Although teens indicated that they felt comfortable talking with their parent(s), they expressed concern about their parent's response, "... you tell them something then they are freaking out then go tell your dad." One group specifically mentioned the difficulty expressing love in the "Mexican" family. One participant stated:

"The Mexican family...they are like afraid like you tell their kids that they love them, I bet you had our parents, we have never 
heard that they love us. They just tell us that by working; that takes over the love part. That hurts you too. You have to grow up thinking that parents love you. You know they do but you have to hear it. They are just like 'no, no.' They don't want to tell you."

Still another teen affirmed this by stating, "When we used to tell her (mom) about that love thing... She used to say, 'My mom never told me.' And then it was like...okay they never told her so then they don't have to tell us and then we don't have to tell our kids. And it just goes on as a cycle."

If teens would not talk with a parent, then a brother or sister was mentioned as next preferable. One teen revealed, "My brother ...[he] put up with a wide range of things. So, I can talk to him about anything. He is the only one that taught me about male sexuality." Several teens stated that they would talk with a good friend. One male responded, "With my best friend. He is younger than me by about a month." Another revealed, "My closest friends, you can always tell them everything." Only two respondents stated that they would talk with a counselor or teacher at school, and then only if it related to a problem at school. One stated, "Probably a counselor or something in school." Another followed with, "Like when I had a problem at school I would tell and go talk to the teacher that had patience with me."

Several teens stated that they would not share their problems with anyone. One teen stated that the problems he has are his, and would keep them to himself. "For me it has always been...something that is really embarrassing sometimes if it is not my friends, I wouldn't tell anyone." Another revealed, "If I couldn't tell my parents then I would just keep it to myself." One male reported, "Usually I would keep it to myself because shit that happened to me was my problem." This was supported when one teen revealed, "I didn't really want to tell everybody else."
Parental perceptions of who their children aged 15-19 felt safe or comfortable with in talking about their problems.

The majority of parents felt that their child came to them when they had a problem. One entire group of participants stated, "With me." Or "Only with me, or his father." Another followed, "With us, his parents." Other confidants mentioned in other groups included cousins, brothers, and sisters.

Not all parents believed that their child came to them with problems. One parent who felt that his child did not discuss her problems with him stated, "Not always at home with us or with mother. Not always because they know that they can be chastised or punished; then they don't talk to avoid the chastisement or punishment. They talk to their friends who don't chastise them or punish them." Another stated, "I think that even trusting us very much, they always have something they want to avoid. They prefer not to discuss it with mom and dad. They do it with a friend."

Adolescents age 11-14 perceptions of what should be included in a sexuality education program for their parent(s).

"Everything" was the consensus of the group. Several participants indicated they did not know because they had not been taught about sexuality yet - either at home or at school. One stated, "Nothing. Because they already took that class. They already know what is going to happen. If you say something wrong they will correct you. They'll be like 'That's not right. I thought I taught you better than that." One stated, "I would teach a program to minors about sex and how to protect themselves." Another added, "Teach them right from wrong." When prodded further to try to probe deeper, one student stated, "I don't get the question. I'm not even in the fifth grade yet."

\section{Parental perceptions of what makes a successful teen pregnancy prevention program for Hispanic youth (aged 11-14.).}

The parents expressed that parents needed to be involved in a successful program sexuality education program. One parent expressed, "I realize that the majority of Hispanic parents 
have a taboo. It is impossible to talk about sex." Suggestions included educating parents so that they might better inform their child, and educating the parents in a school setting (offering a class just for parents). One parent stated, "There is not much we can do about it. But, if we as parents get educated, we can help educating our children." Another followed, "We can't wait for the school to do it. We are more appropriate to educate about sex." Still another stated, "I think that the schools should gather the parents and introduce them to these programs. In all schools here in Washington there should be a class for parents to attend." A final stated, "The parents should go to a class, that is what I think."

Parents also indicated that information on abstinence, risk/harm reduction, consequences, and disease information should be included. One stated, "Tell the girls what is going to happen to them as they grow." Another revealed, "They should show them movies about venereal diseases such as syphilis, gonorrhea and other. So they can see the risk." Another added, "Realize the consequences, the cost of having a child. Perversion so young." Parents indicated that church and biblical teachings should be supported. One stated, "Teach them from the bible." Another followed, "They need to go to church. They avoid problems."

Some parents stated that they preferred that the school provide information and advice about sexuality rather than passing out condoms - their perception of what happens in school sexuality education programs. One father revealed, "I don't like the idea of the school teaching that. Because they tell them that it is alright. That they should only use condoms. The school gives them condoms." Another stated, "My son tells me that they get a lot of condoms instead of advise."

Adolescents age 15-19 perceptions of what should be included in a sexuality education program for their parent(s).

These teens reported that factual information about sexuality was not enough to prevent teen pregnancy. One revealed, "I don't think I would only talk to them about birth control and that stuff. I would also talk to them like they said parenting." Another stated, "...their feelings and conversation and care for the kid...love." Teens stated that programs on how to communicate with parents were a necessary component for success. One teen stated that his father would “...always joke around about it. It didn't really help any, it just made me want to have sex more because I wanted to make my dad happy." Another added, "...they could get the information from somewhere, but just have the information."

Teen expressed a desire for their parents to understand that sexuality is normal. One teen stated, "Let them (parents) understand that at that age their kids already had sex, so telling them not to have sex is not going to help because they already did it." One added, "I think most parents' problems is that they think that sex is really a bad thing that they have been taught either through religion or government type things and they just need to learn that it is like a natural thing and that is actually part of life."

Teens expressed a strong desire for their parent to express love. One teen stated, "I would have to include parenting...care for their kid...love." Another reported, “...you have to tell your kids not just by saying 'I love you.' But by actually showing them."

Parental perceptions of what makes a successful teen pregnancy program for our Hispanic youth (aged 15-19).

Parents indicated that teens needed information on the consequences of sexual choices. One parent stated, "teach them responsibility about sex and the experience they will have... and the consequences of having sex...all kinds of responsibilities... classes about having a baby." Another stated, "Talk about consequences when a girl their age gets pregnant." Another added, "I would recommend about intimacy, especially that intimacy when they are too young is dangerous. I would teach them methods to prevent consequences." Another revealed, "I'd teach them about respect. It is not a game." Finally, one stated, "After they know all this, what else can we tell them? We told them about 
the consequences and experiences. What else could we do for them? Nothing else."

Parents wanted to know and understand what works in prevention, and expressed a willingness to be involved. One stated, "To learn to speak openly with our children." When asked if they would be willing to participate in such programs, all stated simply, "yes."

\section{Adolescents Age 15-19, Who provided sexuality education to you?}

Teens reported that they learned about sexuality from their friends and from a younger or older sibling. One revealed, "Right now my little brother knows a lot of things I thought he wouldn't know." Another added, "School and friends." The groups were divided on parental involvement. Several teens stated that they did talk to a parent. One stated, "My mom, she sat sown and talked to us." Several stated that the parent refused to talk about sexuality, "You will learn about that after you are married...or after you have children." Another added, "Not my parents. They would be like, get away, that's private."

Teens stated that they did not take sexuality education in grade five seriously. Males revealed that they were uncomfortable in a mixed sex group when talking about sexuality. They would have preferred a "one-on-one" educational approach. One stated, "I didn't want to talk about it in front of girls or in front of my friends and stuff." Another added, "When I was in school it wasn't very tempting to talk about it in front of other girls and shit. So I would skip that day. I wasn't at school that day just because of that reason." Females reported that childbirth films were not age-appropriate. One stated,

"They are just wasting money doing that kind of stuff, because instead of helping they are not. They are adding to the problem. In 5 th grade, half the stuff they were talking about they would just giggle and laugh. It was so funny. In front of the screen they all just kept laughing. Because you don't have that body yet."
Parents of adolescents aged 15-19: When your child was 11-14 years old, did anyone provide sexuality education for him/her?

Parent's perceptions were divided on this item. Some parents reported they were the primary person that provided sexuality information for their child. One parent stated, "I reply to my daughter if she asks me. I try to answer with soft words as it should be." Another added, "It is better to talk to them, for them to know what to do." Another countered, "All depends. We teach them. They will do it with or without our permission." Another parent stated, "As parents, we should advise them, because sometimes they learn from friends, and they tell more than they should know. We should explain them, otherwise it may happen to them. That is my idea."

Several parents indicated that they became embarrassed when trying to discuss sexuality with their child. One parent stated, "The subject of sex embarrasses some of us. If they ask questions we don't answer until we don't have another choice. Once the subject is obvious, we don't know how to avoid it. The majority of us don't talk about it." Another added, "Also my children sometimes ask me, "What did you know when you were our age?' We told them that children were brought by someone up there (implying God). If they ask how it was done, I tell them that when they grow up I'll tell them." Another parent revealed, "It is embarrassing because we don't know how to answer. I don't like it. I don't like it."

\section{Summary}

Teen pregnancy rates continue to decline for most populations in the U.S; however Hispanic teen pregnancy rates continue to remain steady or rise. Developing successful Hispanic teen pregnancy prevention programs requires an understanding of variables that contribute to the problem.

Yakima County has one of the highest Hispanic populations in the state, and ranks among the top three counties in teen pregnancy (VISTAPH, 2003). During 2002, Planned Parenthood of Central Washington, funded by a grant from the Centers for Disease Control and Prevention, 
collaborated with Central Washington University to design a formative study to develop a Hispanic teen pregnancy prevention program. Titled "The Latina Project," researchers developed a qualitative focus group design study to establish baseline information in developing a Hispanic teen pregnancy prevention program.

Both adolescents and parents agreed that mothers were their most trusted confidants. Other family members followed. While younger adolescents did not appear willing to discuss components of sexuality education programs in focus groups, older adolescents disclosed that sexuality education programs should not moralize, but recognized their sexual experience. Older teens wanted programs for parents to include information on communication and parenting skills. Parents wanted programs to focus on consequences, protection, and responsibility. Parents wanted church and biblical teachings to be supported. They did express a willingness to be more involved in the education of their child. Older adolescents stated that they received sexuality information from friends first, then family members. Most parents reported that they believed they were the ones to discuss sexuality with their child. Some parents revealed that they felt too embarrassed to discuss the topic with their child.

Hispanic families tend to share a tight bond (Schust, 1997). It is not surprising to find that both adolescents and parents in this study reported that the mother was the first person young people talked to when discussing their problems. This study confirms a recent study by Acklard \& Neumark-Sztainer (2001) who reported that parents were the preferred confidants of teens. Hispanic family unity is a strength that can be built upon in designing successful teen pregnancy prevention programs.

While both younger and older adolescents stated that they confided in their mother when discussing their problems, many older teens indicated that they did not receive sexuality information form their parent. Most parents, however, stated that they taught their child about sexuality. This divergence of opinion may indicate that parents are not providing enough information to their children, possibly because they may be too embarrassed to discuss sexuality openly. This finding supports traditional Hispanic values that imply that sexuality should be discussed only between a husband and wife (Garcia-Preto, 1996; Schust, 1997). Since many parents expressed an aversion to discussing sexuality with their child, we should support the important role of schools and clinics in providing comprehensive sexuality education that is available to all.

Since teens revealed they obtain sexuality information from friends, peer education programs may be successful with this population. Friends were mentioned by teens as trusted confidants and as a source of sexuality information. Parents also recognized importance of friendships in the life of their child. Peer sexuality education programs may help bridge the gap of information between parent and child. Educators can provide the content suggested by parents utilizing the communication channels preferred by adolescents.

Adolescents and parents differed on the preferred content of teen pregnancy prevention programs. Adolescents wanted information on sexuality in a non-judgmental or moralizing manner and expressed interest in programs that discuss communication and parental roles. Parents preferred programs that emphasized abstinence, responsibility and consequences. This preferential divergence may be difficult to overcome. It seems that the most effective programs will have content that reflects the values and preferences of both adolescents and parents.

Continuing studies with this population are necessary to more fully understand variables to be included in a successful teen pregnancy prevention program. Developing more successful recruiting techniques for parent participation and increasing the sample sizes in all groups are needed.

A recent report issued by the Pew Hispanic Center \& Kaiser Family Foundation (2002) stated that "...the rapid growth of the Latino 
population in the recent years is among the most important demographic trend[s] shaping the future of the U.S., and yet there are a great many questions...about this population." (p.2) Exploring the content of effective teen pregnancy prevention programs in the Hispanic population will lead to more effective interventions. It will also support stronger training programs for future health educators who will most certainly be working in settings with significant Latino populations.

\title{
References
}

Ackard, D. M., \& Neumark-Sztainer, D. (2001). Health care information sources for adolescents: Age and gender differences on use, concerns, and needs. Journal of Adolescent Health, 29, 170-176.

Boonstra, H. (2002). Teen pregnancy: Trends and lessons learned. The Guttmacher Report on Public Policy, Feb., 6-10.

Centers for Disease Control and Prevention. (2000). Youth risk behavior surveillance - U. S. 1999. Morbidity and Mortality Weekly Report, 49(SS05).

Garcia-Preto, N. (1996). Latino families: An overview. In M. McGoldrick, J. Giordano, \& J. Pearce (Eds.), Ethnicity and Family Therapy (pp. 141-154). New York: Guilford.

Goodyear, R. K., Newcomb, M. D., \& Allison, R. D. (2000). Predictors of Latino men's paternity in teen pregnancy: Test of a mediational model on childhood experiences, gender role attitudes, and behaviors. Journal of Counseling Psychology, 47, 116-128.

O’Donnell, L., Stueve, A., SanDoval, A., Duran, R., Haber, D., Atnafou, R., Johnson, N, Grant, U, Murray, H, Juhn, G, Tang, J, \& Piessens, P. (1999). The effectiveness of the reach for health community youth service learning program in reducing early and unprotected sex among urban middle school students. American Journal of Public Health, 89, 176-181.

Schust, C. S. (Ed.)(1997). Community health education and promotion: A guide to program design and evaluation. Gaithersburg, MD: Aspen Publishers.

Santelli, J. S., Lowry, R., Brener, N. D., \& Robin, L. (2000). The association of sexual behaviors with socioeconomic status, family structure, and race/ethnicity among US adolescents. American Journal of Public Health, 90, 1582-1588.

\section{Acknowledgements}

This research was supported, in part, by a grant from the Centers for Disease Control and Prevention.

\author{
Author Information \\ M. S. Madlem, Ph.D. \\ Associate Professor \\ Central Washington University \\ Cathy Bambrick, M.S., RD \\ Clarity Consulting \\ Erin Fishburn, B.S. \\ Samantha Ball-Garza, B.A. \\ Jani Iverson, M.S. \\ Planned Parenthood of Central Washington \\ Yakima, WA \\ Mary Pellicer, M.D. \\ Physician
}

